\title{
A Method of Location Selection for Rural Highway Transportation Service Facilities Based on GIS
}

\author{
Lili Huang ${ }^{1}$, Shuangying $\mathrm{Xu}^{2}$, Languang $\mathrm{Lu}^{3}$, Liangfei $\mathrm{Xu}^{3}$, Yanjing $\mathrm{Li}^{1} \&$ Yaping Zhang ${ }^{1}$ \\ ${ }^{1}$ School of Automotive Engineering, Lanzhou Institute of Technology, Gansu, China \\ ${ }^{2}$ Automotive School, Chang'an University, Xi'an, China \\ ${ }^{3}$ Automotive Research Institute, Tsinghua University, Beijing, China \\ Correspondence: Lili Huang, School of Automotive Engineering, Lanzhou Institute of Technology, 01 \\ Gongjiaping Donglu, Qilihe District, Lanzhou, Gansu 730050, China. Tel: 86-189-1904-8877. E-mail: \\ huanglili_lily@126.com
}

Received: January 17, 2020

Accepted: February 17, $2020 \quad$ Online Published: March 15, 2020

doi:10.5539/jas.v12n7p53

URL: https://doi.org/10.5539/jas.v12n7p53

The research is financed by Gansu Province Department of Education program under the Higher Education Scientific Research Gansu of China Project entitled "Design and Research on the Film Membrane Seeding Machine of Multifunctional Hole Broadcasting Seeding and Direct-inserted Ginseng Seedling”, Item Number: 2017A-109.

\begin{abstract}
To efficiently organize and optimize travel modes, meet safe, convenient and comfortable travel requirements for passengers, and promote the sound development of transportation infrastructure on rural highways, this paper reviews the common location selection methods for highway passenger stations, and compares the advantages and disadvantages of existing methods. Using rural highway passenger station as the research subject, we proposed a scientific, systematic and practical method for location selection based on GIS (Geographic Information System) technology. At the same time, we used AHP (Analytic Hierarchy Process) to establish, and to qualitatively and quantitatively analyze the model — in a scientific and rational framework- to determine the location of the stations. Location input data collected by this method are comprehensive, accurate and quickly-calculated. The entire site selection process is visualized in the form of pictures, which provides a method and theoretical reference value in the future for site selection construction on Rural Highway Transportation Service Facilities. Herein, this paper uses passenger stations as a research object and uses the stated methods above to achieve the desired results.
\end{abstract}

Keywords: location selection, rural transportation service facilities, GIS, AHP

\section{Introduction}

With the gradual improvement of the status of the transportation industry in the Chinese national economy, the central government is providing strong support for the construction of highway passenger transportation hubs and related facilities. During this construction process, the locations of these transportation infrastructure sites will be critical to the future development of road infrastructure and passenger transportation. Scientific and rational site selection enable us to fully utilize the distribution function of the stations, ensure safe and efficient road travel, alleviate traffic pressure effectively in urban centers, promote sound regional development of these areas, and shorten the long-distance travel of operating vehicles. Reducing energy consumption and emissions of vehicles, optimizing rural and urban traffic-oriented strategies, and achieving harmony between urban and rural transportation development and land use (Lili, 2013), this research can promote the development of rural transportation and optimize the way that people travel. This method of location selection can provide some theoretical guidance for other site selections in the future.

\section{Method Review}

The study of site selection can be sourced from the basic Euclidean space problem raised by Pierre de Fermat (Wei, 2005). On this basis, Webber (1909) set up a model of the median problem in Euclidean space. Then 
Weiszfeld (1937) proposed an algorithm for solving the median problem of the famous Euclidean space in the community location problem that further supports Webber's research. And Hakimi (1964) proposed a P-median problem based on the network graph. With the goal of obtaining better economic benefits, Huanjiang (2001) based the experience of layout and site selection by establishing a road passenger station layout and location model, and considering the parameter determination and calculation steps to optimization decision on the layout and location of highway passenger station. Then Qiao and Qipeng (2003) established a multi-level evaluation index system for selecting layout schemes according to the factors influencing the layout of highway passenger transportation stations. Considering the influencing factors and the fuzzy attributes of the evaluation indicators, combined with the Analytic Hierarchy Process (AHP). With the mature development of the theory, Louveaux (2005) used stochastic optimization methods to carry out in-depth research on different problems in locating sites after this research. At the same time, Kuby and Lim (2005) studied the location of the filling station of the candidate facility at a designated point. With the limited driving distance of vehicles, Kuby's research increased the number of cars on the O-D line that could reach the final destination. And Ye and Li (2007) studied the stochastic optimization problem in which customer demand obeys a stochastic distribution of vehicle path selection and location selection. Then Berman and Drezner (2008) built a heuristic algorithm for the facility based on the P-neutral location problem. Schiitz et al. (2008) further optimizes the location results through the Lagrangian relaxation heuristic algorithm. The above studies provide a valuable theoretical basis for this study.

Summing up all of the above, location theory can be split into three categories: the central theory, peripheral theory, and comprehensive theory. Location methods commonly based on these three theories that are center of gravity method, P-center method, and P-media method (Lorena \& Senne, 2004). Among them, the center of gravity method is appropriate for the arrangement of individual facilities. Although data collection via this method is relatively easy to obtain and the calculation simple and easy to understand, when the location of a single road passenger station is selected and multiple passenger stations need to be built in the planned area, the location method no longer applies. The P-center problem and the P-median problem are all static-determined location problems. The model idealizes the actual situation, thus making the method only plausible in the theoretical model stage. In practice, though, the model structure remains complex and difficult to understand and function. It cannot be widely used in projects. Focusing on the limitations of existing model methods, this paper proposes a spatial location method based on GIS (Geographic Information Systems).

\section{GIS Model}

In order to coordinate the dynamic relationship between population flow, material flow, energy flow, and information flow in geographic space, and to achieve dynamic balance and sustainable development, GIS uses its spatial analysis function based on the establishment of a data model to simulate the real world. Digital simulation and dynamic analysis of spatial states, dependencies, interactions, changing laws, feedback laws, and modulation mechanisms of various elements (Xiaobing, 2008). In particular, its spatial analysis function can quickly and flexibly analyze and simulate objects, use computers to numerically collect various geographic information elements of the geographical environment, build an effective data management system, and use function models to perform geographic functions. Comprehensive analysis quickly captures the information available to respond to the needs of applications and research, and finally showed the results in graphical and numerical form.

\subsection{Model Layer Establishment}

The location selection of highway passenger station is a multi-factor problem. This paper applies spatial analysis function of ArcGIS. In the carrier city area of the highway passenger station, according to the principle and influencing factors of the site selection. Firstly, setting up an independent layer for each influencing factor. Then, using the topological relationship in GIS, the influence factors fall into three blocks, which named point layer, line layer and plane layer. The following case data are provided by Pucheng County of Shaanxi Province.

\subsubsection{Point Layer}

The points show the administrative units, enterprises, hospitals, schools, tourist attractions, commercial points, other transportation port stations, chemical plants, and supporting service facilities in the city. These elements interact with road passenger stations and closely relate to the travel of residents. The Arccatalog database of the GIS software can manage, collect and store urban geographic information of the map in the form of data. At the same time, the related attribute as the constituent elements data values in the map are also added through the attribute editing to created layers for each point feature of the region. Finally, all the layers are combined into point layer so that is in favor of buffer analyzing for each point feature.

In the point layer mainly considers the elements related to the travel of residents and the site of the passenger station. The various elements will be classified in order to simplify the element type of the point layer. Take 
Pucheng County as an example, the elements are divided into administrative units, water supply stations, tourist attractions, enterprises, schools, commercial hotels (commercial centers and hotels), banks, hospitals, etc. According to the map of Chengguan Town in Pucheng County, which are positioned different layers and integrated on the goal layer of the case illustrated in Figure 1.

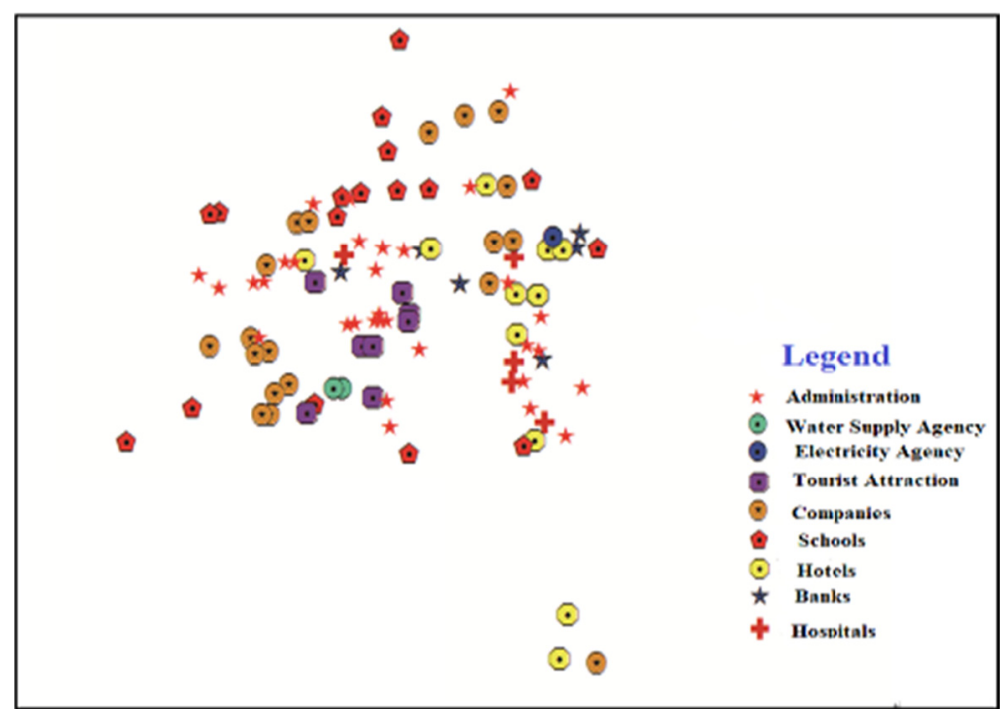

Figure 1. Point layer map

\subsubsection{Line Layer}

The line mainly reflects the traffic routes that go through the city, including national highways, provincial highways, urban trunk roads, secondary trunk roads and expressways. The precondition for the construction of passenger stations says there are good traffic network conditions. Passengers, roads, vehicles, and passenger stations are four essential components of the road transportation system. These four elements constitute a series of closed-loop in this road transportation system. As long as one element does not comply with the standard or fails, this circuit is not feasible to complete the entire journey. Whether the road conditions are good determines the traffic flow and flow direction on the route, so in the process of site selection, road conditions are particularly critical for site selection. This study mainly considers national roads, provincial roads, main roads, highways, and secondary roads in urban and foreign traffic organizations. Depending on the road grade, different road line layers are appropriate to provide for the city's traffic lines, and then these layers are combined in one layer. The line layer of the case established in this paper is shown in Figure 2.

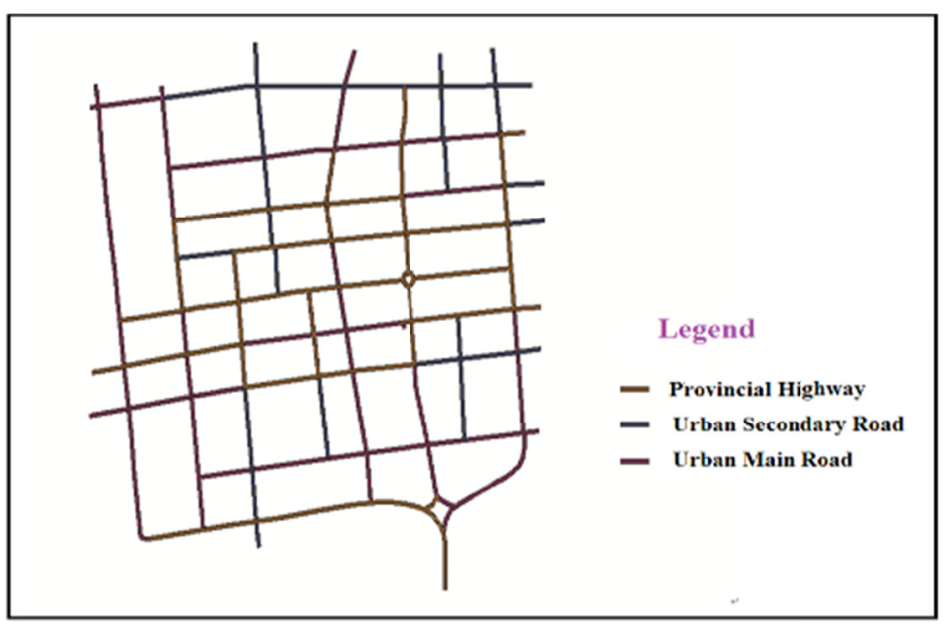

Figure 2. Road layer network map 


\subsubsection{Plan Layer}

The plane indicates that the city is divided into distinct communities. Each community is composed of separate cells. The population distribution of each community is recorded separately, and then the population is edited in the attributes of each cell for subsequent buffer analysis. We analyzed the population's restrictions on the location of the passenger station and establish a buffer zone for each cell. Depending on the actual situation of Chengguan Town in Pucheng County, the city is divided into six discrete plane layers. Each plane layer includes various cell layers, and the population of each cell is edited in its respective attributes. Finally, combining them into a graph as showing in Figure 3.

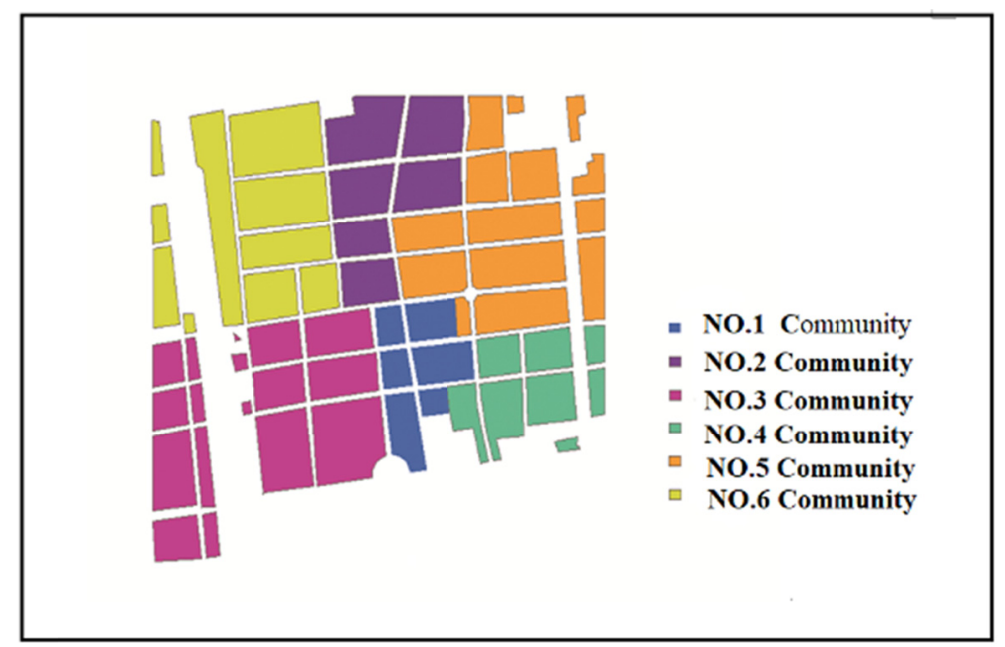

Figure 3. Case community layer

\subsection{Model Buffer Analysis}

The Buffer Wizard function in GIS spatial analysis is used to establish a common buffer for objects in the point layer and the line layer, and the cells in the polygon layer are created according to the population distribution. If the traffic flow on a given route is known, one can also create a property buffer for the road-line layer, so that the results are more in line with actual demand. In this study, due to the limited accessibility of certain data of the research object, a common buffer was created for the road line layer in the case analysis.

\subsubsection{Point Layer Buffer Establishment}

The passenger station is the site where passengers gather densely and have the largest amount of traffic. The safety hazard is the biggest. Considering people's travel convenience and reducing the number of transfers, safety issues must be taken into consideration. Therefore, in the study of determining the buffer radius, consider the different intimate relationship between the point factors and the station, and use different buffer radii, such as the school and hospital away passenger station site buffer radius $\mathrm{r}=200 \mathrm{~m}$, other factors buffer Radius $\mathrm{r}=100 \mathrm{~m}$, etc., the buffering results are shown in Figure 4. 


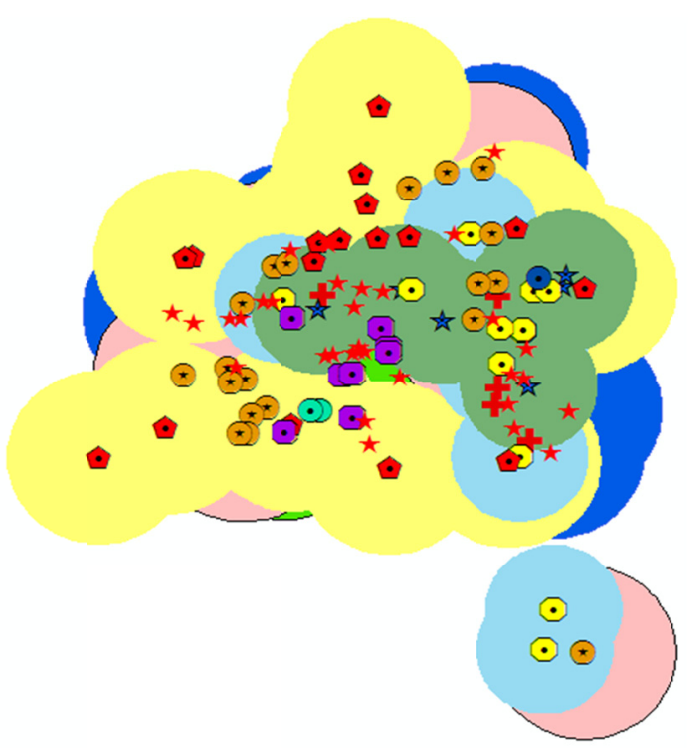

Figure 4. Point object buffer map

\subsubsection{Line Layer Buffer Creation}

Roads have an inductive effect on the development of passenger stations. Construction of passenger stations must ensure a reliable connection with national roads, provincial roads, urban main roads, highways and other convenient transportation. Therefore, the site needs to be considered before planning to build a station. Within the scope of these road traffic conditions for facilitating the connection with urban public transportation and reducing the number of transfers, the passenger station should not be too far away from the main traffic routes of the city. While considering the convenience, it is also important to ensure the safety of traffic. If the passenger station is chosen at the traffic intersection, although it could satisfy the convenience of residents in all directions, traffic pressure followed by safety hazards to people and cars. Based on above reasons, this study comprehensively considers the structure and scale of the city, according to the road grade of the city to buffer the road, so the station within $100 \mathrm{~m}$ of the national highway and $50 \mathrm{~m}$ of the provincial road or the urban main road. If the traffic flow on each line is known that can also be edited in the respective attributes in the form of weight, and more objective results will be obtained after buffering analysis. Depending on the GIS buffer analysis function based on this condition, the buffered result of the road is illustrated in Figure 5.

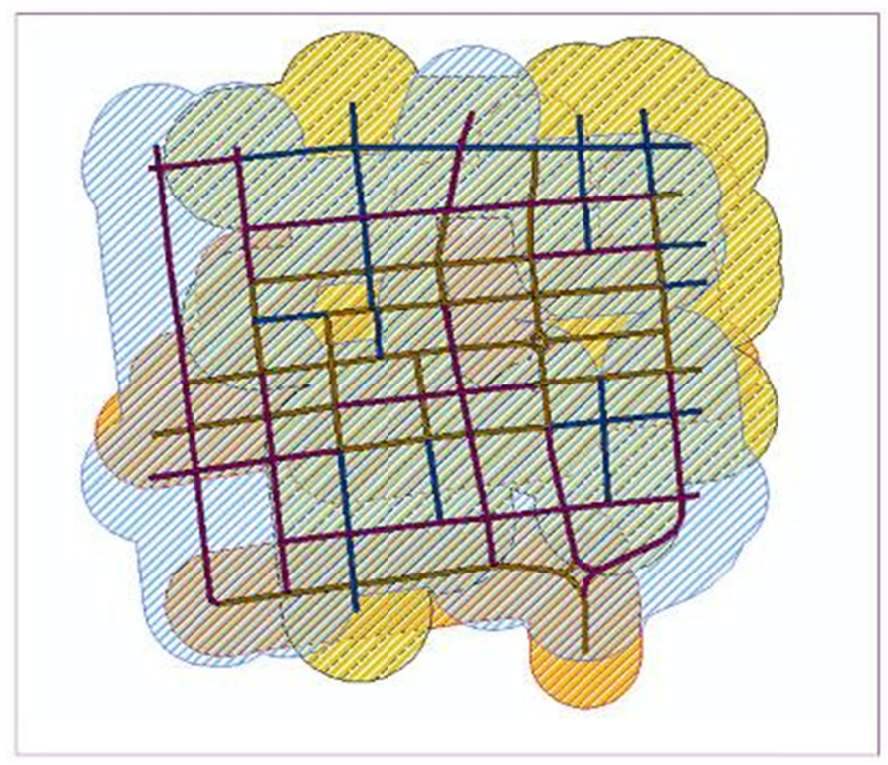

Figure 5. Road buffer diagram 


\subsubsection{Plane Layer Buffer Creation}

Population is part of the most important factors affecting traffic flow, so the plane layer mainly reflects the population density of each community. According to the plane layer buffer analysis function, the attribute buffer needs to be established. Therefore, Firstly, the population of each community at Chengguan Town in Pucheng County is edited in the respective population attribute values in the plane layer. The population distribution of the community is shown in table 1 , which is provided by Pucheng County.

Table 1. Community population of every distribution in Chengguan Town

\begin{tabular}{|c|c|c|c|c|c|c|}
\hline ID $\quad$ Community & NO.1 & NO. 2 & NO.3 & NO.4 & NO. 5 & NO.6 \\
\hline 1 & 2635 & 2643 & 2314 & 2642 & 1638 & 1310 \\
\hline 2 & 3317 & 2212 & 2143 & 3239 & 6375 & 1125 \\
\hline 3 & 4023 & 3310 & 418 & 2354 & 7236 & 3357 \\
\hline 4 & 3472 & 1640 & 387 & 3182 & 2465 & 4578 \\
\hline 5 & 2205 & 3368 & 2813 & 2471 & 6072 & 4683 \\
\hline 6 & 1648 & 4027 & 1725 & 1734 & 6831 & 5865 \\
\hline 7 & & & 1028 & 755 & 6247 & 5963 \\
\hline 8 & & & 1689 & 923 & 3371 & 4784 \\
\hline 9 & & & 3658 & & 2929 & 5589 \\
\hline 10 & & & 5385 & & 1107 & 2030 \\
\hline 11 & & & 2973 & & 1043 & \\
\hline 12 & & & 3064 & & 1339 & \\
\hline 13 & & & 2715 & & 2409 & \\
\hline 14 & & & 2064 & & 2638 & \\
\hline 15 & & & 599 & & & \\
\hline 16 & & & 835 & & & \\
\hline 17 & & & 708 & & & \\
\hline
\end{tabular}

Note. NO.i is the $i^{\text {th }}$ community's name, the data of the blank in the table is not counted.

The demographics in each community sector are compiled and edited in their respective attributes. The densely populated areas are basically located in the city center known from the perspective of the population of the city. In order to avoid causing huge traffic pressure on the city center, the buffer condition should consider the "centrism" mentioned above and the overall planning and combine with the future development plan for the city. Herein, we should realize the passenger station is more suitable to be in the surrounding area than a densely populated urban center, but not too remote to prevent an increase in the number of transfers.

According to the above Table 1, the area with a population of 2,500-6,831 people is mainly concentrated in the center of the city. If the passenger station is selected in these areas, it can meet the convenience of travel and shorten the travel time, but the city passenger and traffic flow can lead to severe traffic pressure in the central area. Considering the development of the city and the principle of location selection, the buffer layer of the plane layer is among the population of 1000-2500 people, the finally obtained plane buffer is shown in Figure 6 . 


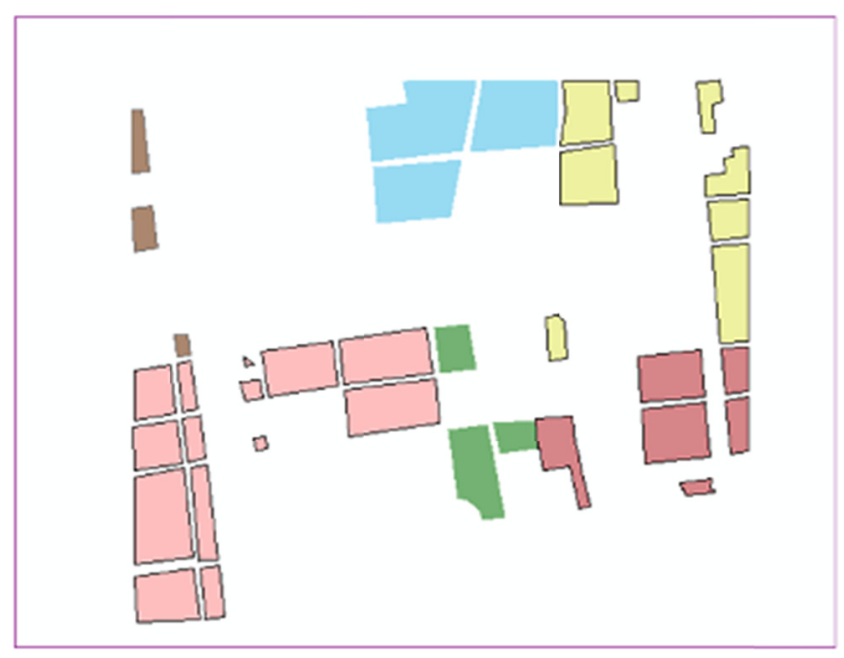

Figure 6. Plane layer buffer map

\subsection{Graph Stacking Analysis}

The data layer of the above influencing factors is superimposed by the superposition analysis function of GIS. Then all the buffer layers are superimposed and intersected in the same method. Depending on the principle of site selection, confirmed the superimposed range of the factors affecting the site selection. However, the intersect function is used to satisfy the intersection of the comprehensive factors among each point, line and plane layer, according to the superposition and intersection function, the nine candidate sites are respectively obtained, which are $\mathrm{H} 1, \mathrm{H} 2, \mathrm{H} 3, \mathrm{H} 4, \mathrm{H} 5, \mathrm{H} 6, \mathrm{H} 7, \mathrm{H} 8, \mathrm{H} 9$ showed in Figure 7.

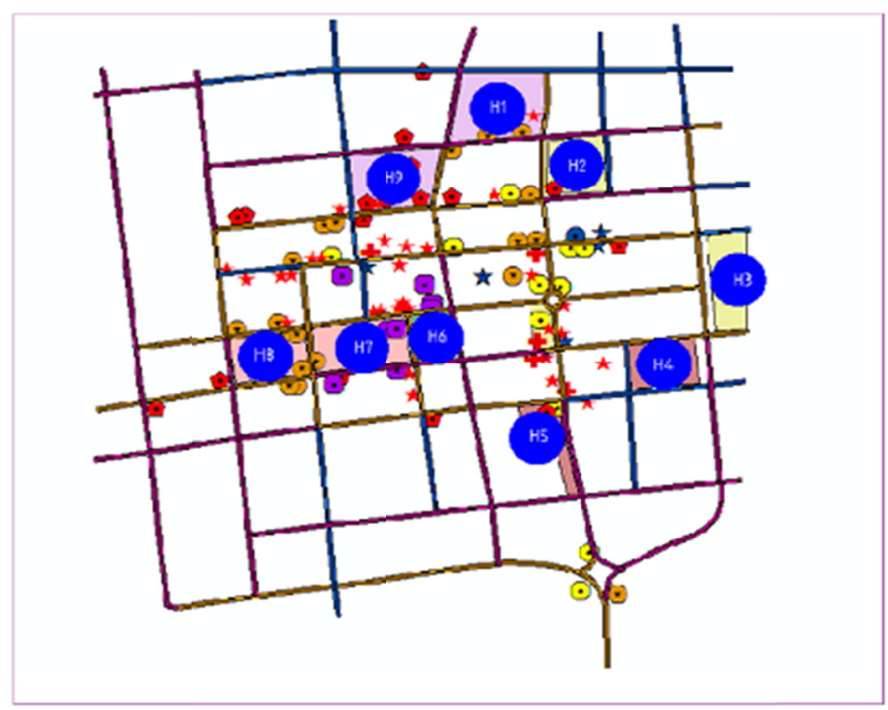

Figure 7. Candidate point map based on GIS spatial analysis

\subsection{Spatial Location Model Solving}

Analytic Hierarchy Process (AHP) is a systematic and hierarchical analysis method combining qualitative and quantitative methods (Yingai, Feng, \& Weizheng, 2008). According to the nature of AHP, a hierarchical structure analysis map is constructed for the passenger station site selection problem, and then each factor of each level is quantified one by one to obtain the relative weight value of each factor in each layer. The weight is judged and combined with the generalized objective function model to evaluate the suitability of the passenger station location (Wei \& Lianyu, 2006). 


\subsubsection{Establish a Hierarchical Model}

Based on deeply analyzing the practical problems, the relevant factors are decomposed into several levels from top to bottom depending on different attributes. The factors of the same layer are subordinate to the factors of the upper layer or influence the upper factors, while controlling the subsequent, the factors of the layer are affected by the underlying factors. The topmost layer is the target layer where usually is only one factor, the bottom layer is the scheme or object layer, and there can be one or several levels in the middle as the criterion or indicator layer. While there are too many criteria (such as more than nine), the sub-criteria layer should be further decomposed. According to the selection site principle of Passenger Station, the economic, social benefits and environmental impacts of the Chengcheng Town in Pucheng County as the carrier city to confirm its the hierarchical analysis structure as shown in Figure 8.

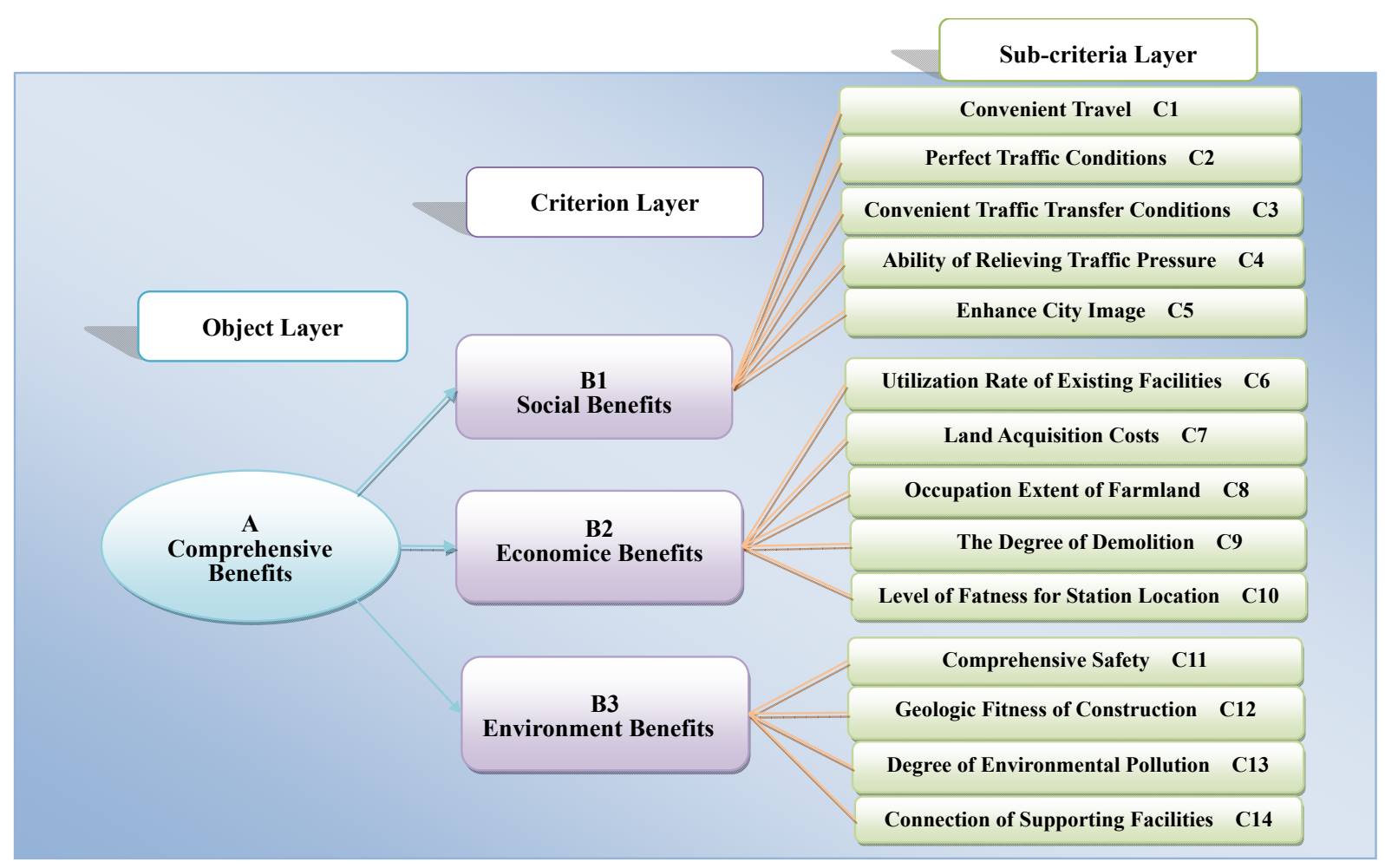

Figure 8. Hierarchical analysis structure

\subsubsection{Scale Method}

By comparing the influencing factors of each site to obtain a quantitative judgment matrix (Hao \& Da, 1993), the popular scale of 1-9 of AHP that proposed by Professor T. L. Saaty (Yingai, Feng, \& Weizheng, 2008) is applied in this study. According to the research of psychologists, the limit ability of people to distinguish information levels is $7 \pm 2$ (Baofa, 2004) Formulated in Table 2. 
Table 2. Table of 1-9 Scales

\begin{tabular}{ll}
\hline Importance Scale Value & Definition \\
\hline 1 & Importance: $i=j$ \\
3 & Importance: $i>j$ \\
5 & Importance: $i>j$ \\
7 & Importance: $i>>j$ \\
9 & Importance: $i>>>j$ \\
$2,4,6,8$ & Importance Scale Value corresponding to the intermediate state between the above two judgments \\
Reciprocal & If $j$ and $i$ are compared, Judgment Value: $a_{j i}=\frac{1}{a_{i j}}, a_{i i}=1$ \\
\hline
\end{tabular}

\subsubsection{Constructing a Judgment Matrix}

The analytic hierarchy process is a practical method of presenting the relative importance levels in the form of the ratio of the two schemes. When constructing a pairwise comparison matrix, starting from the second layer of the hierarchical model, the pair of comparison factors and the 1-9 comparison scale are utilized to compare the same layer of factors belonging to each factor of the upper layer. Until the lowest level of the hierarchy model. The target layer that affects the location of the passenger station is $\mathrm{A}$, the criterion layer is $\mathrm{B}$, and the sub-criteria layer is $\mathrm{C}$. The importance weight of the factors is $\mathrm{C} 1, \mathrm{C} 2, \ldots \mathrm{C} 14$.

In this method there are only one target layer in the case which evaluates the total score, three factors in the criteria layer that are social benefits, economic benefits and environmental conditions; and fourteen sub-criteria layers which are based on factors, principle and selections affecting the location of highway passenger stations. The factors for each layer are compared by pairwise to obtain a matrix of judgment matrices shown in Table 3 6.

Table 3. Judgment matrix between two comparison of the criteria layer

\begin{tabular}{llll}
\hline $\mathrm{A}$ & $\mathrm{B}_{1}$ & $\mathrm{~B}_{2}$ & $\mathrm{~B}_{3}$ \\
\hline $\mathrm{B}_{1}$ & 1 & $1 / 2$ & 4 \\
$\mathrm{~B}_{2}$ & 2 & 1 & 4 \\
$\mathrm{~B}_{3}$ & 0.25 & 0.25 & 1 \\
\hdashline$\lambda_{\max }=3.054$ & $\mathrm{CI}=0.027$ & $\mathrm{RI}=0.58$ & $\mathrm{CR}=0.046 \leq 0.1$ \\
\hline
\end{tabular}

Table 4. Judgment matrix of sub-criteria layer to criterion layer B1

\begin{tabular}{|c|c|c|c|c|c|}
\hline $\mathrm{B}_{1}$ & $\mathrm{C}_{1}$ & $\mathrm{C}_{2}$ & $\mathrm{C}_{3}$ & $\mathrm{C}_{4}$ & $\mathrm{C}_{5}$ \\
\hline $\mathrm{C}_{1}$ & 1 & 0.5 & 0.5 & 0.5 & 0.25 \\
\hline $\mathrm{C}_{2}$ & 2 & 1 & 2 & 2 & 0.5 \\
\hline $\mathrm{C}_{3}$ & 2 & 0.5 & 1 & 2 & 0.5 \\
\hline $\mathrm{C}_{4}$ & 2 & 0.5 & 0.5 & 1 & 0.25 \\
\hline $\mathrm{C}_{5}$ & 4 & 2 & 2 & 4 & 1 \\
\hline$\lambda_{\max }=5.436$ & $\mathrm{CI}=0.109$ & & 1.12 & & $\leq 0.1$ \\
\hline
\end{tabular}

Table 5. Judgment matrix of sub-criteria layer to criterion layer B2

\begin{tabular}{|c|c|c|c|c|c|}
\hline $\mathrm{B}_{2}$ & $\mathrm{C}_{6}$ & $\mathrm{C}_{7}$ & $\mathrm{C}_{8}$ & $\mathrm{C}_{9}$ & $\mathrm{C}_{10}$ \\
\hline $\mathrm{C}_{6}$ & 1 & 0.5 & 0.5 & 0.5 & 0.25 \\
\hline $\mathrm{C}_{7}$ & 2 & 1 & 2 & 2 & 0.5 \\
\hline $\mathrm{C}_{8}$ & 2 & 0.5 & 1 & 2 & 0.25 \\
\hline $\mathrm{C}_{9}$ & 2 & 0.5 & 0.5 & 1 & 0.25 \\
\hline $\mathrm{C}_{10}$ & 4 & 2 & 4 & 4 & 1 \\
\hline$\lambda_{\max }=5.136$ & $\mathrm{CR}=0.034$ & & 0.58 & & $\leq 0.1$ \\
\hline
\end{tabular}


Table 6. Judgment matrix of sub-criteria layer to criterion layer B3

\begin{tabular}{lllll}
\hline $\mathrm{B}_{3}$ & $\mathrm{C}_{11}$ & $\mathrm{C}_{12}$ & $\mathrm{C}_{13}$ & $\mathrm{C}_{14}$ \\
\hline $\mathrm{C}_{11}$ & 1 & 0.5 & 1 & 0.25 \\
$\mathrm{C}_{12}$ & 2 & 1 & 0.5 & 0.25 \\
$\mathrm{C}_{13}$ & 1 & 2 & 1 & 0.25 \\
$\mathrm{C}_{14}$ & 4 & 4 & 4 & 1 \\
\hdashline$\lambda_{\max }=4.184$ & $\mathrm{CI}=0.061$ & & $\mathrm{RI}=0.9$ & $\mathrm{CR}=0.68 \leq 0.1$ \\
\hline
\end{tabular}

\subsubsection{Calculation Weight $\left(\omega_{i}\right)$ and Consistency Check}

The judgment matrix judged by the above experts is hierarchically sorted, usually the square root method is widely used to calculate the weight value of each factor in each judgment matrix for its criterion according to the rank (Mingbao \& Lianyu, 2003). While the maximum eigenvalue and corresponding eigenvector of the judgment matrix are obtained, at the same time the consistency test is also passed according to the random consistency index and the consistency ratio, which means that the normalized feature is obtained as well. The vector is the relative importance weight of a certain level indicator to a related indicator of the previous level. If the test does not pass, the comparison matrix needs to be reconstructed.

(1) Calculate the geometric mean of all elements in each row of the judgment matrix by Equations 1 and 2:

where, $\bar{\omega}_{i}=\left(\overline{\omega_{1}}, \overline{\omega_{2}}, \ldots \overline{\omega_{n}}\right)^{T}$.

$$
\overline{\omega_{i}}=\sqrt[n]{\prod_{j=1}^{n} a_{i j}} \quad i=1,2, \ldots \mathrm{n}
$$

$$
\omega_{i}=\frac{\overline{\omega_{i}}}{\sum_{i=1}^{n} \overline{\omega_{i}}} \quad i=1,2, \ldots \mathrm{n}
$$

where, $\bar{\omega}^{*}=\left(\overline{\omega_{1}}, \overline{\omega_{2}}, \ldots \overline{\omega_{n}}\right)^{T} . \bar{\omega}^{*}$ : The Approximate Value of the obtained feature vector and also The Relative Weight of each factor.

(2) Calculate eigenvalue of maximum of the judgment matrix $\lambda_{\max }$ by Equation 3 :

$$
\lambda_{\max }=\sum_{i=1}^{n} \frac{\left(A \overline{\omega^{*}}\right)_{i}}{n \overline{\omega_{i}}}
$$

where, $\left(A \bar{\omega}^{*}\right)_{i}$ is the $i^{\text {th }}$ element of $A \omega^{*}$ vector.

(3) Calculate weights $\left(\omega_{i}\right)$ of the judgment matrix:

$\omega_{1}=01.345, \omega_{2}=0.547, \omega_{3}=0.109$;

In the same way to get:

$\omega_{11}=0.087, \omega_{12}=0.229, \omega_{13}=0.173, \omega_{14}=0.114, \omega_{15}=0.398 ;$

$\omega_{21}=0.084, \omega_{22}=0.220, \omega_{23}=0.145, \omega_{24}=0.110, \omega_{25}=0.441$;

$\omega_{31}=0.120, \omega_{32}=0.142, \omega_{33}=0.170, \omega_{34}=0.569$.

It can be seen from the above calculation results that the social impact factors and economic influence factors are taken into consideration when selecting the location of the highway passenger station. However, from the current traffic environment problems manifested by road transport, the environmental influence factors are becoming more and more important in the transportation system. When studying transportation problems, we must pay more attention to and consider the traffic environment conditions. A suitable transportation environment can guarantee the sustainable development strategy of the passenger station.

(4) Evaluation model of the site of the passenger station:

The criteria affecting the location of highway passenger stations are hierarchical. These principles are organically linked to a mathematical model by establishing a generalized objective function (Liping Qian \& Shide Zhao, 2005) shown as Equation 4. 


$$
Z=\sum_{i=1}^{n} Z_{i}=100 \sum_{i=1}^{n} K_{i} \sum_{j=1}^{k}\left(K_{i j} \times K_{i j}^{*}\right)
$$

The total scores for the evaluation of the $i^{\text {th }}$ candidate site. The first criterion layer has $\mathrm{n}$ influencing factors, $i$ is the $i^{\text {th }}$ influencing factor of the first criterion layer, $i=1,2, \ldots \mathrm{n} ; Z_{i}$ is the total score of the $i^{\text {th }}$ criterion in the first criterion layer; $j$ is the $j$ criterion of the $i^{\text {th }}$ factor in the first criterion layer in the sub-criteria layer, $j=1,2, \ldots \mathrm{k} . \mathrm{k}$ is the $i^{\text {th }}$ factor in the first criterion layer at the sub-criteria layer. $\omega_{i}$ represents the weight of the $i$ factor in the first criterion layer; $\omega_{i j}$ represents the weight of the $j^{\text {th }}$ factor of the $i^{\text {th }}$ factor in the first criterion layer in the sub-criteria layer; ${ }^{*} i j$ represents the actual weight of the $j^{\text {th }}$ factor of the $i$ factor of the sub-criteria layer in the sub-criteria layer.

(5) Calculate actual weights of candidate sites:

Combining the candidate points of passenger stations based on GIS space selection, field investigation and research, and based on the results of field investigation and analysis, we invited experts to give weights to each factor affecting the candidate sites, and then to use the evaluation model to calculate a candidate point. The actual contribution weights are shown in Table 7.

Table 7. Actual contribution weight values of each candidate site

\begin{tabular}{|c|c|c|c|c|c|c|c|c|c|}
\hline $\mathrm{H}$ & $\mathrm{H}_{1}$ & $\mathrm{H}_{2}$ & $\mathrm{H}_{3}$ & $\mathrm{H}_{4}$ & $\mathrm{H}_{5}$ & $\mathrm{H}_{6}$ & $\mathrm{H}_{7}$ & $\mathrm{H}_{8}$ & $\mathrm{H}_{9}$ \\
\hline $\mathrm{C}_{1}$ & 0.8 & 0.7 & 0.8 & 0.8 & 0.8 & 0.8 & 0.8 & 0.8 & 0.8 \\
\hline $\mathrm{C}_{2}$ & 0.7 & 0.8 & 0.8 & 0.8 & 0.9 & 0.8 & 0.9 & 0.9 & 1 \\
\hline $\mathrm{C}_{3}$ & 0.6 & 0.8 & 1 & 1 & 1 & 0.8 & 1 & 0.8 & 0.7 \\
\hline $\mathrm{C}_{4}$ & 0.8 & 0.8 & 0.9 & 1 & 1 & 0.8 & 1 & 0.9 & 0.8 \\
\hline $\mathrm{C}_{5}$ & 1 & 1 & 1 & 1 & 1 & 1 & 1 & 1 & 1 \\
\hline $\mathrm{C}_{6}$ & 0.8 & 0.9 & 0.8 & 0.9 & 1 & 0.8 & 0.9 & 0.8 & 0.8 \\
\hline C7 & 0.8 & 0.8 & 0.6 & 0.8 & 0.8 & 0.7 & 0.8 & 0.8 & 0.6 \\
\hline C8 & 1 & 1 & 1 & 1 & 1 & 1 & 1 & 1 & 1 \\
\hline C9 & 0.6 & 0.6 & 0.6 & 0.8 & 0.8 & 1 & 1 & 1 & 1 \\
\hline $\mathrm{C} 10$ & 0.6 & 0.6 & 0.7 & 0.6 & 0.6 & 0.6 & 0.8 & 0.6 & 0.6 \\
\hline C11 & 1 & 1 & 1 & 1 & 1 & 1 & 1 & 1 & 1 \\
\hline $\mathrm{C} 12$ & 1 & 1 & 0.8 & 0.9 & 0.8 & 1 & 1 & 1 & 1 \\
\hline $\mathrm{C} 13$ & 1 & 1 & 0.8 & 0.9 & 1 & 1 & 1 & 1 & 1 \\
\hline $\mathrm{C} 14$ & 0.6 & 0.8 & 0.8 & 0.8 & 0.8 & 0.7 & 0.9 & 0.8 & 0.8 \\
\hline
\end{tabular}

Note. In the table, Hi represents the $i^{\text {th }}$ candidate site, and Ci represents the $i^{\text {th }}$ influencing factor.

According to the above evaluation model, the total evaluation score of each candidate is calculated as follows in Equation 5:

$$
Z_{H_{1}}=\sum_{i=1}^{3} Z_{i}=100 \sum_{i=1}^{3} K_{i} \sum_{j=1}^{5}\left(K_{i j} \times K_{i j}^{*}\right)
$$

where, $Z_{H_{1}}=76.14$.

In the same way we can calculate $Z_{H_{2}}=79.52, Z_{H_{3}}=80.28, Z_{H_{4}}=82.67, Z_{H_{5}}=83.95, Z_{H_{6}}=79.95, Z_{H_{7}}=$ 90.44, $Z_{H_{8}}=82.95, Z_{H_{9}}=80.35$.

\subsection{Evaluation of Example Results}

Nine candidate sites obtained based on GIS spatial analysis techniques and the actual demands of Chengguan Town in Pucheng County, it need to select four passenger station sites among them which spread over the east, west, north and south four directions at Chengguan Town in Pucheng county. However, according to the total evaluation score of each candidate point, there are three candidate points on the north side that are $H_{1}, H_{2}$ and $H_{9}$. Although the total score of $H_{9}$ in the north side candidate points is the highest, it is not appropriate to set up a station due to $H_{9}$ near the school, so the candidate point $H_{2}$ is more suitable to be the North Passenger Station. The East Terminal is selected between $H_{3}$ and $H_{4}$, and finally the candidate point $H_{4}$ is determined as the site of the East Terminal based on the evaluation of a total score. Since the candidate point $H_{5}$ is adjacent to 
the provincial road pass through the main north-south line in Chengguan Town, it is very suitable for the passenger station that sends passengers to the south, because the south side is the external main traffic artery of Chengguan Town in Pucheng County, $H_{5}$ is the best choose to build a long-distance passenger station. Combined with the evaluation results obtained by the analytic hierarchy process, the candidate point $\mathrm{H}_{7}$ is finally determined as the site of the West Passenger Station. In conclusion, depending on GIS space selection and field investigation and analysis, the final road passenger station sites are $\mathrm{H}_{2}, \mathrm{H}_{4}, \mathrm{H}_{5}$, and $\mathrm{H}_{7}$.

\section{Conclusion and Outlook}

This paper mainly introduces the definition, composition and spatial function analysis of GIS, and briefly describes the space application field of GIS and the advantages of its application in space location. It mainly applies the application of GIS spatial analysis technology to the location selection of rural highway passenger stations. The results of the study confirm tree rural passenger transportation stations and urban passenger transportation station location spread in Pucheng county, where rural transportation and urban transportation connects, and also can promote the development of rural transportation. The method analyzed in detail and obtained candidate points that are graded and ranked by the analytic hierarchy process so that the obtained results conforms more to real-life situations. In addition, with the current development of new energy technologies, the method can be applied to the location planning of new energy storage facilities and charging facilities such as charging piles for new energy electric vehicles in the countryside. However, since current data is still not comprehensive and conditions are not yet available, this research can only contribute to any further progress made in the field of GIS technology.

\section{References}

Baofa, Z. (2004). Economic Forecasting and Economic Decision-making. Beijing: Economic Science Press.

Berman, O., \& Drezner, Z. (2008). The p-median problem under uncertainty. European Journal of Operational Research, 189(1), 19-30. https://doi.org/10.1016/j.ejor.2007.05.045

Hakimi, S. L. (1964). Optimum Locations of Switching Centers and the Absolute Centers and Medians of a Graph. Operations Research, 12, 450-459. https://doi.org/10.1287/opre.12.3.450

Hao, W., \& Da, M. (1993). Analytic hierarchy process scale evaluation and new scale method. Journal of Systems Engineering Theory and Practice.

Huanjiang, C. (2001). Research on the layout and site selection of highway passenger station. Highway Traffic Science and Technology, 18(3).

Kuby, M., \& Lim, S. (2005). The flow-refueling location problem for alternative fuel vehicles. Socio-Economis Planning Sciences, 39, 125-145. https://doi.org/10.1016/j.seps.2004.03.001

Lili, H. (2013). Research on site selection and layout of highway passenger transportation station. Xi'an: Chang'an University.

Liping, Q., \& Shide, Z. (2005). Application of Analytic Hierarchy Process in Site Selection of Landfill Sites-Taking Harbin City as an Example. Safety and Environmental Engineering, 12(4), 22-26.

Lorena, L. A. N., \& Senne, E. L. F. (2004). A Column Generation Approach to Capacitated P-Median Problem. Computers and Operations Research, 31(6), 863-876. https://doi.org/10.1016/S0305-0548(03)00039-X

Louveaux, F. Y. (2005). Discrete stochastic location models. Annals of Operations Research, 6, 23-34. https://doi.org/10.1007/BF02027380

Mingbao, P., \& Lianyu, W. (2003). Systems Engineering and Transportation. Tianjin: Tianjin People's Publishing House.

Qiao, X., \& Qipeng, Y. (2003). Multilevel fuzzy comprehensive evaluation of urban highway passenger station layout. Journal of Huazhong University of Science and Technology, 20(4).

Schiitz, P., Stougie, L., \& Tomasgard, A. (2008). Stochastic facili-ty location with general long-run costs and Convex short-run costs. Computer \& Operations Research, 35(9), 2988-3000. https://doi.org/10.1016/j.cor. 2007.01.006

Webber, A. (1909). Ueber den Standort der Industrien. Tubingen, Germany: Verlag J. C. B. Mohr.

Wei, W., \& Lianyu, W. (2006). Application of Analytic Hierarchy Process in Location Selection of Passenger Stations in Central City. Journal of Hebei University of Technology. 
Wei, Y. (2005). Research on the problem of interception and location of network service facilities. Wuhan: Huazhong University of Science and Technology.

Weiszfeld, E. (1937). Sur 1e Point pour Lequel la Somme des Distances de n points Donnesest Minimum. Tohoku Mathematical Journal, 43, 355-386.

Xiaobing, Z. (2008). Research on GIS-based Primary School Layout and Location Planning. Shanghai: Tongji University.

Ye, W., \& Li, Q. (2007). Solving the stochastic location-routing problem with genetic algorithm. Proceedings of nternational Conference on Management Science\& Engineering (pp. 429-434).

Yingai, G., Feng, T., \& Weizheng, L. (2008). Operational research. Tsinghua University Press.

\section{Copyrights}

Copyright for this article is retained by the author(s), with first publication rights granted to the journal.

This is an open-access article distributed under the terms and conditions of the Creative Commons Attribution license (http://creativecommons.org/licenses/by/4.0/). 